\title{
Erratum to: Purification and Characterization of $\beta$-Glucosidase Produced by Trichoderma Citrinoviride Cultivated on Microalga Chlorella Vulgaris ${ }^{1}$
}

\author{
K. Muensaen and S. M. Kim* \\ Department of Marine Food Science and Technology, Gangneung_Wonju National University, \\ Gangneung 201_702, Republic of Korea \\ *e-mail:smkim@gwnu.ac.kr \\ Submitted February 25, 2019; accepted for publication February 25, 2019
}

DOI: $10.1134 / \mathrm{S} 0003683819110012$

The name of the first author should read Muensaen.

The original article can be found online at

https://doi.org/10.1134/S000368381501010X.

\footnotetext{
${ }^{1}$ The article is published in the original.
} 